\title{
Influence of Message Framing and Product Type of Metaphorical Ads on Advertising Preference
}

\author{
Chao-Ming Yang ${ }^{1, *}$, Tzu-Fan Hsu ${ }^{2}$ \\ ${ }^{1}$ Department of Visual Communication Design, Ming Chi University of Technology, New Taipei City, Taiwan \\ ${ }^{2}$ Department of Commercial Design, Chung Yuan Christian University, Taoyuan City, Taiwan
}

Email address:

yangcm@mail.mcut.edu.tw (Chao-Ming Yang), nightshift1943@gmail.com (Tzu-Fan Hsu)

\section{To cite this article:}

Chao-Ming Yang, Tzu-Fan Hsu. Influence of Message Framing and Product Type of Metaphorical Ads on Advertising Preference. Psychology and Behavioral Sciences. Vol. 4, No. 2, 2015, pp. 79-89. doi: 10.11648/j.pbs.20150402.17

\begin{abstract}
Although previous studies have indicated that metaphorical advertisements have high persuasiveness, consumers are frequently affected by message framing and product type that lead to varying value preferences and decisions. This study adopted a $2 \times 2$ between-subjects experimental design to operate the two independent variables of metaphorical message framing (positive metaphor vs. negative metaphor) and advertised product type (symbolic product vs. utilitarian product) to verify the research hypotheses and test the influence of the two variables on advertising preference. Four significant results were obtained: (a) message framing affected advertising preference, and the advertising preference for positive metaphors surpassed that for negative metaphors; (b) product type affected advertising preference, and the advertising preference for symbolic products exceeded that for utilitarian products; (c) symbolic products using a negative metaphor obtained a relatively higher level of advertising preference; and (d) utilitarian products using a positive metaphor acquired a relatively higher level of advertising preference. Metaphorical advertisements are a persuasive tool for breaking consumer psychological defense. Nevertheless, optimizing the persuasiveness of metaphorical advertisements still relies on metaphorical message framing and product type. The results of this study can provide compelling and clear references for advertising practitioners to formulate message strategies and realize creativity in the future.
\end{abstract}

Keywords: Metaphorical Advertisement, Message Framing, Product Type, Decision Frame, Prospect Theory

\section{Introduction}

Metaphors generate imagination [43] and convince people through an analogy between two objects. Metaphors are a type of destabilization trope [29] and are widely favored by advertisers because of their strong persuasiveness [32]. Metaphorical advertisements adopt a pattern that is based on the analogical connection derived from juxtaposing target and vehicle [28]. Target denotes the target space, which is also the content of advertised products or services, whereas vehicle refers to the objects from the source space that are used to establish analogical connections with the advertised products or services. This type of advertising patterns prompts consumers to process information more thoroughly and attracts their curiosity and interest toward the brand [25].

McQuarrie and Mick [28] found that metaphorical advertisements enhance consumers' ability to recall the said information and reinforce their positive attitudes toward the information. Pawlowski, Badzinski, and Mitchell [34] focused on children and determined that, although children cannot correctly interpret the implications of metaphorical advertisements, their recall and perception of these advertisements are more effective than those of traditional advertisements. Accordingly, the rhetorical techniques of metaphors and the persuasive effects of advertisements are positively associated. However, a review of literature on metaphorical advertisements by this study showed that despite scholars' praises about the advertising effects of metaphors, they have focused primarily on comparing types of metaphors without examining the implications of metaphorical messages. Consequently, this study adopted the concept of message framing to examine the role that message type plays in metaphorical advertisements and to analyze the relationship between product type and advertising preference.

Advertisements are merely vehicles for conveying product information, and obtaining complete product information from these vehicles is difficult for consumers. Without complete information, consumers and their ultimate decisions are frequently affected by the ways messages are presented. 
This factor for final decisions is referred to as message framing effects [39]. In their prospect theory, Tversky and Kahneman [39] indicated that people tend to make risk-averse decisions when exposed to positive messages but make risk-seeking decisions when exposed to negative messages.

In other words, for consumers making a decision, the unpleasant emotions incurred from loss overweigh the pleasant emotions derived from gain. Thus, different message presentations frequently affect final decisions. Levin and Gaeth [22] conducted a study using same quality beef cuts but differing lean-fat percentage labels (i.e., $75 \%$ lean vs. $25 \%$ fat). They observed that most consumers selected cuts labeled 75\% lean (positive message), whereas only few consumers opted for cuts labeled $25 \%$ fat (negative message). Meyerowitz and Chaiken [31] determined that negative messages for combating breast cancer (i.e., lack of self-examination easily leads to breast cancer) can stimulate stronger positive attitudes and behavioral intention in women compared with positive messages (e.g., self-examination prevents breast cancer).

All of these studies have indicated that people's value preferences and decision-making behaviors vary with different information presentations even when they encounter two conditions with the same result. Haley and Baldinger [10] stated that consumer preference for advertisements is the optimal indicator for measuring the effects of advertising communication. Therefore, this current study combined metaphorical advertising patterns with the theory of message framing effects to investigate the influence of message framings and product types in metaphorical advertisements on advertising preference. Overall, the following three objectives were formulated in this study:

- Investigate the influence of different message framings indicated in metaphorical advertisements on advertising preference.

- Investigate the influence of different product types in metaphorical advertisements on advertising preference.

- Investigate the process of how the interaction between the message framings and product types of metaphorical advertisements influence advertising preference.

\section{Literature Review}

\subsection{Essence of Metaphorical Advertising}

According to Kaplan [15], metaphor was originally applied in rhetoric and later expanded from lingual forms to cover visual and graphic uses. Metaphor creates a new cognitive relationship between two originally irrelevant objects through their formal similarities. This relationship denotes a target and a vehicle, which are objects derived from the target space and source space, respectively [33]. The earliest research related to metaphor was on analogy. The literature indicates that cognitive psychologists and neurolinguists have endeavored to investigate the reasons for the brain and cognitive functioning's pursuit of analogical persuasiveness. Similar research intentions were subsequently applied in advertisements and further constituted the research scope of metaphorical advertisements [32].

Boozer, Wyld, and Grant [3] maintained that genuine metaphorical advertisements should involve three basic characteristics: (a) creating the effects of word, phrase, and sentence conversion and substitution; (b) withdrawing the meaning from a daily object and applying it to another less common object; and (c) implying a similarity and relationship between objects or experiences through analogy. In addition, Gentner and Markman [8] indicated that the workings of metaphor can be explained using the concept of analogy and that analogical thinking patterns, which are ubiquitous in human life, constitute a channel for learning knowledge as well as a crucial mechanism for solving problems.

In psychological discourses, metaphor is regarded as relational reasoning based on comparing the similarities between two objects, and this psychological cognition is termed cross-conceptual domain comparison [19]. Black [2] referred to the target and vehicle of a metaphor as the primary subject and secondary subject, respectively, in the interaction theory, the core of which is in the duality of objects. In the framework of interaction theory, the relationship among metaphorical topics is not based on invariable or unidirectional mapping, and no preexisting relationships are required among topics. Furthermore, the establishment of a metaphorical relationship among objects can be interpreted using their similarities.

Lakoff and Jonhson [19] divided the essence of metaphor into the source domain and target domain. The elements and structure hidden in the source domain exceed those in the target domain. By learning through experiential similarities, the structure of the source domain is projected onto the target domain, and thus, a new cognitive system is reconstructed. Lakoff and Jonhson [19] further argued that, as long as the invariance principle is not violated, the elements or structure of the source domain would naturally correspond with the image-schematic of the target domain through people's cognitive operations, and thereby, metaphorical concepts can be interpreted. Jeong [14] asserted that metaphorical concepts are grounded in the relational structure of two objects. The relationship evokes the semantic memory of people, and the link provided by the memory assists the audience in constructing and organizing metaphorical concepts more systematically. According to the aforementioned discourses, the conveyance and comprehension of metaphorical concepts, in addition to being related to psychological cognition, are the results of mutually referencing and analogizing objects. Metaphorical messages are conveyed and interpreted through the interaction between the similarities of objects.

\subsection{Message Framing Effect}

Since Tversky and Kahneman [39] proposed the decision frame, this theory has been widely applied in various fields. In addition, this theory has been used to demonstrate that people make different decisions according to differences in personal 
conditions and problem statements, from which the concept of message framing effects was subsequently derived, substantially influencing the studies on consumer behavior [26]. Specifically, framing effects refer to a circumstance in which two decision problems with a completely identical property induce different reactions in people because they are expressed or stated differently. Message framing refers to whether advertising messages are conveyed through positive or negative phrasings.

Positive message framing is defined as a message's emphasis on the benefits conveyed by a brand or on the potential advantages consumers can obtain in a certain condition. Negative message framing denotes a message's presentation of conditions unfavorable to the brand or of the potential damage incurred if consumers do not use a certain product [9]. Message framing is a common maneuver in advertisements because it imperceptibly affects the behavioral decision making of consumers and is associated with a message's persuasiveness [26]. For example, "Quitting smoking will increase your chances of preventing the onset of lung cancer," is a message presented with positive framing, whereas "Not quitting smoking will decrease your chances of preventing the onset of lung cancer" is a message presented with negative framing [40].

When message framing is associated with advertising, positive message framing in advertisements emphasizes the benefits gained by consumers from using the advertised product, whereas negative message framing accentuates the possible loss of interest incurred from not selecting the advertised product $[31,26,43]$. According to literature, the difference in message framing substantially affects consumer purchase intention [6]. Experimental participants showed relatively favorable evaluations [22] and a strong advertising preference for positive messages [36]. Furthermore, positive messages produce relatively high persuasiveness [36].

However, when people expect to see negative message framing, they tend to process messages more carefully [38]. A study indicated that negative message framing, compared with positive message framing, attracts the attention of audiences more easily and urges consumers to devote more mental effort to processing the message [36].

Pratto and John [35] argued that human beings theoretically react more violently and intensely to negative incidents than to positive incidents because they frequently think that "pleasure is simply less urgent than pain" [40]. Furthermore, message framing effects are closely associated with consumer involvement levels $[16,26]$. In particular, when people face negative messages involving health risks or altered personal needs, their involvement in the messages increases, and the effects of negative message framing increase [40].

Wong and McMurray [40] explained that negative messages with the audience highly involved are typically more persuasive because negative message framing produces fear perception, which is highly correlated with personal concerns, in the audience. However, Grewal et al. [9] determined that positive messages become more persuasive than negative messages do when consumers are less involved.
In short, previous studies have differed in their conclusions regarding message framing effects. The critical factor for such differences, as we speculated, should be whether the content of a message is associated with personal concerns. This association guides consumers to assess whether they should further process a message, and their engagement level is termed message involvement [26].

\subsection{Advertised Product Types}

According to previous studies, advertised products on the market can be divided into symbolic products and utilitarian products [1]. When purchasing symbolic products, consumers focus on whether the products can produce sensory gratification and affective effects [42] or interest and entertainment [12]. This type of product accentuates the emotions perceived by consumers and the symbolic meanings embedded in the products. Purchasing this type of product indicates the fulfillment of the ideal self-image [17]. Symbolic products make consumers identify product benefits through the aesthetics, interest, and symbolic aspects of the products [12], evoke emotions in consumers, and stimulate their self-esteem and self-satisfaction on the psychological level [27].

Symbolic products are defined as products based on sensibility in the Foote, Cone, and Belding grid (FCB Grid) [41]; and the products can be divided into high-involvement/sensibility and low-involvement/sensibility. High-involvement/sensibility products are priced higher and emphasize the emotions perceived by consumers, and the consumers think in a feel-learn-do mode. Consumer behavior toward this type of product corresponds with the characteristics of self-esteem in the psychological model, and therefore, the consumer is called a feeler. By contrast, low-involvement/sensibility products are priced lower and can satisfy personal tastes, and consumers think in a do-feel-learn mode. Consumer behavior toward this type of product fulfills the characteristics of self-satisfaction in social theory, and therefore, the consumer is called a reactor.

Compared with symbolic products, utilitarian products involve more rational appeals with emphases on functionality, convenience, and economic benefits [42]. These products are presented in a utilitarianism-oriented manner to evoke the consumers' purchase desires, and consumers determine whether the products are worth purchasing on the basis of product practicality [11]. Vaughn [41] defined utilitarian products as products based on rational thinking in the FCB Grid. According to consumer involvement, utilitarian products are divided into high-involvement/rationality and low-involvement/rationality products.

High-involvement/rationality products are highly priced and emphasize functionality. Thinking in a learn-feel-do mode, consumers actively investigate the prices and functions of these products to evaluate product utility. Consumer behavior toward utilitarian products satisfies the traditional economic model, and therefore, the consumer is called a thinker.

By contrast, low-involvement/rationality products are relatively lowly priced, and consumers purchase them 
according to habit and convenience. The advertisements of these products are not a crucial factor affecting a consumer's purchase decision but information for consumers to compare product differences. Generally, consumers of this type of product become loyal to a particular brand through daily habits; however, consumers may accept several brands. Consumers purchase low-involvement/rationality products according to their habits and therefore think in a do-learn-feel mode. Consumer behavior toward these products corresponds with the behavioral patterns in responsive theory; thus, the consumer is considered a doer.

Ang and Lim [1] indicated that, compared with utilitarian products, symbolic products may be perceived by consumers to be more sophisticated and exciting because they can serve highly self-expressive and affective purposes. Therefore, in advertising appeal, the advertising messages of symbolic products would gain more appreciation from consumers than those of utilitarian products. Conversely, when the benefits of functionality and utility are displayed in the advertisements for utilitarian products, the sincerity and down-to-earth attitudes perceived by consumers in the messages surpass those associated with symbolic products.

\section{Research Design}

\subsection{Hypotheses and Experimental Framework}

Initially, previous studies have indicated that message framing significantly affects consumer purchase intention [6]. Positive messages attract relatively favorable evaluations [22] and a strong advertising preference from experimental participants [36]. In addition, positive messages are more persuasive than negative messages when consumers are in a low-involvement condition [9]. Moreover, differences in advertised product types can indirectly affect the subsequent emotional reactions of consumers [5]. Different types of advertised product or service create different advertising communication effects [1]. According to the aforementioned literature, this study constructed Hypotheses 1and 2:

- H1: Differences in the message framings of metaphorical advertisements affect advertising preference.

- H2: Differences in the product types of metaphorical advertisements affect advertising preference.

Symbolic products are relatively more exciting for consumers because they serve highly self-expressive and affective purposes [1]. When symbolic products are described using negative messages, consumers are induced to expend more mental effort to process the messages [36]. Therefore, this study inferred that consumers may show a high preference for advertising messages after they comprehend the messages. In addition, the advertisements for utilitarian products emphasize functions and effects. The sincerity and down-to-earth attitudes perceived by consumers in the messages surpass those associated with symbolic products [1]. Consequently, this study inferred that utilitarian products stated in positive messages enable consumers to identify product benefits more easily and thus show a high preference for advertising messages. Accordingly, this study proposes Hypotheses 3 and 4, and the experimental framework is illustrated in Fig. 1.

- H3: Advertisements for symbolic products receive a high advertising preference when using negative metaphorical statements.

- H4: Advertisements for utilitarian products receive a high advertising preference when using positive metaphorical statements.

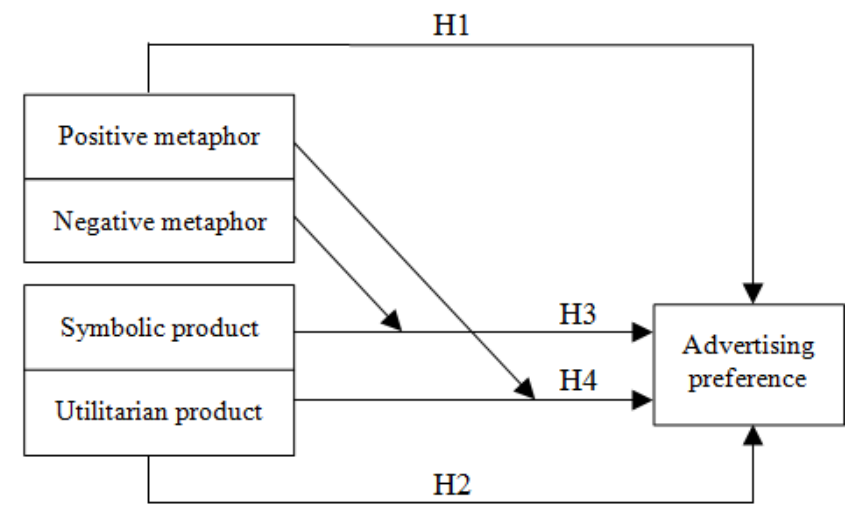

Figure 1. Experimental framework.

\subsection{Experimental Variables}

One of the two independent variables in this study was message framing. According to Wong and McMurray [40] and Zhang and Buda [43] metaphorical advertisements were divided into two message types in this study, namely positive metaphors (i.e., using metaphorical skills to combine the similarities between objects with the benefits of advertised products to convey the positive effects of using the products) and negative metaphors (i.e., using metaphorical skills to combine the similarities between objects with the benefits of advertised products to convey the negative effects of using the products). The other independent variable was product type. Referring to Vaughn [41] and Ang and Lim [1] advertised products were divided into symbolic products (i.e., products emphasizing the emotions perceived by consumers, pleasure, or interest that enable consumers to evaluate products from the gratification of personal tastes) and utilitarian products (i.e., products emphasizing functionality, convenience, and economy that enable consumers to evaluate products from practicality and utility).

The dependent variable in this study was advertising preference, defined as consumers' behavioral tendency in which they exhibit a persistent liking or disliking to the advertising stimuli of product brands [23]. The questionnaire in this study was formulated from cognitive and emotional facets according to Lutz, Mackenzie, and Blech [24]. The overall questionnaire contained six items (three for cognitive and three for emotional facets) to measure the preference levels of participants for an advertisement. The items included "I think this advertisement is easy to understand," "I think this advertisement meets consumer needs," "I think this 
advertisement is presented vividly and lively," "I'm impressed by this advertisement," "I give positive evaluations to this advertisement," and "I like the presentation of this advertisement." A 7-point Likert scale was used after the statement of each item for participants to evaluate their advertising preference. The degree of agreement was divided into seven levels: strongly disagree, disagree, somewhat disagree, neither agree or disagree, somewhat agree, agree, and strongly agree.

\subsection{Experimental Design and Stimuli}

This study adopted a $2 \times 2$ between-subjects experimental design to operate the two independent variables of message framing (positive metaphors vs. negative metaphors) and product type (symbolic products vs. utilitarian products). Chewing gum was selected from low-involvement products as the representative of symbolic products, and toothpaste was employed to represent utilitarian products according to the theory of the FCB Grid [41]. Subsequently, experimental stimuli were sought on the basis of these four product types.

Initially, 57 advertisements that met the objectives of this study were collected from ADVERTOLOG website (http://www.advertolog.com). Subsequently, three experts specializing in advertising design were invited to confirm the experimental stimuli, and finally, eight print advertisements were selected (Figs. 2-5).
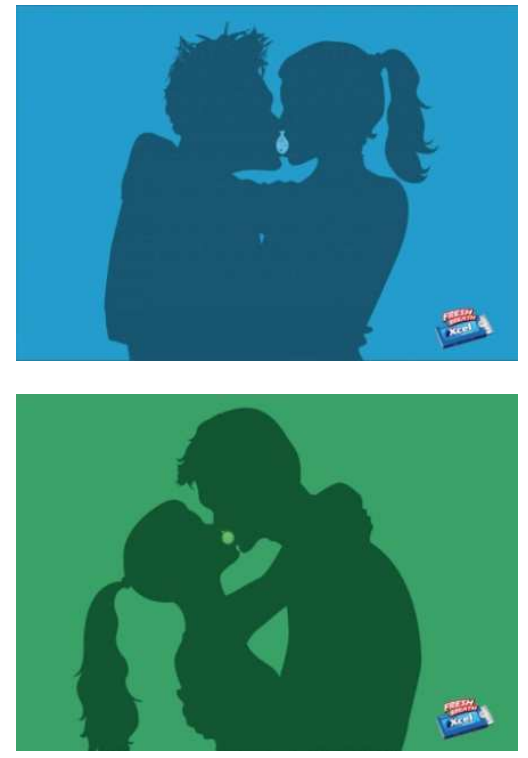

(Advertisements obtained from ADVERTOLOG)

Figure 2. Symbolic product advertisement with positive metaphor

The entire experiment consisted of four conditions (Conditions A-D), which were symbolic product-positive metaphor, symbolic product-negative metaphor, utilitarian product-positive metaphor, and utilitarian product-negative metaphor. Every experimental condition was assigned two serial advertisements with the same appeal, and all of these advertisements had been published in print media. We believed that participants would express their true attitudes if published advertisements were used as experimental stimuli
(Table 1)
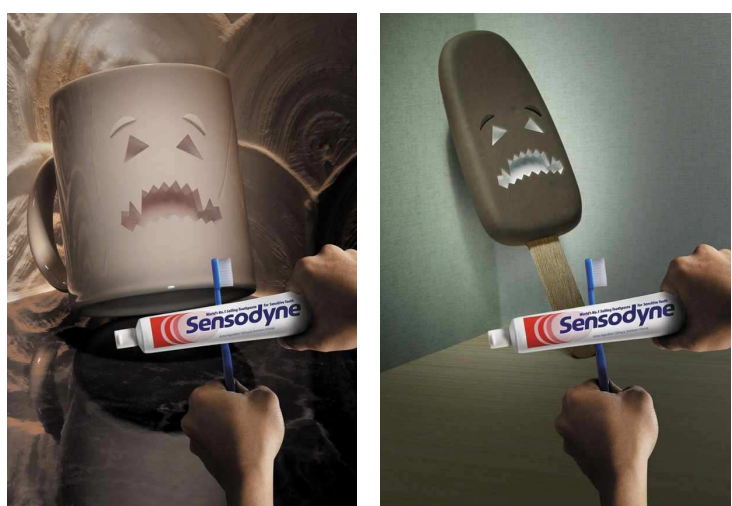

(Advertisements obtained from ADVERTOLOG)

Figure 3. Utilitarian product advertisement with positive metaphor.
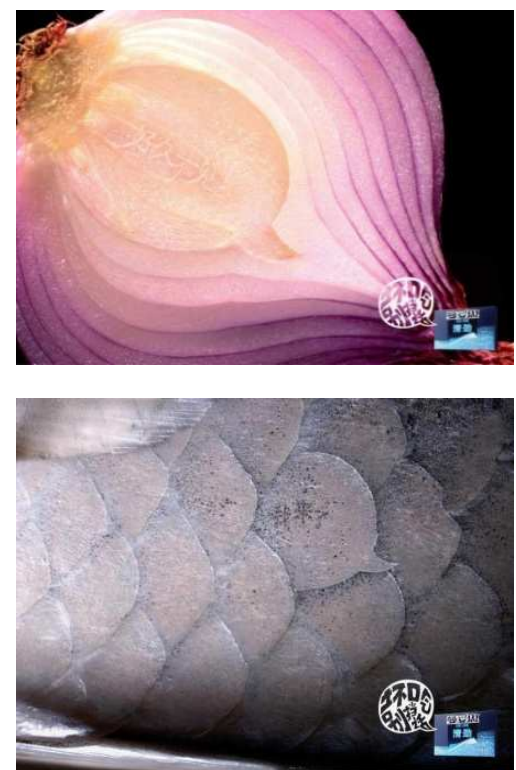

(Advertisements obtained from ADVERTOLOG)

Figure 4. Symbolic product advertisement with negative metaphor.
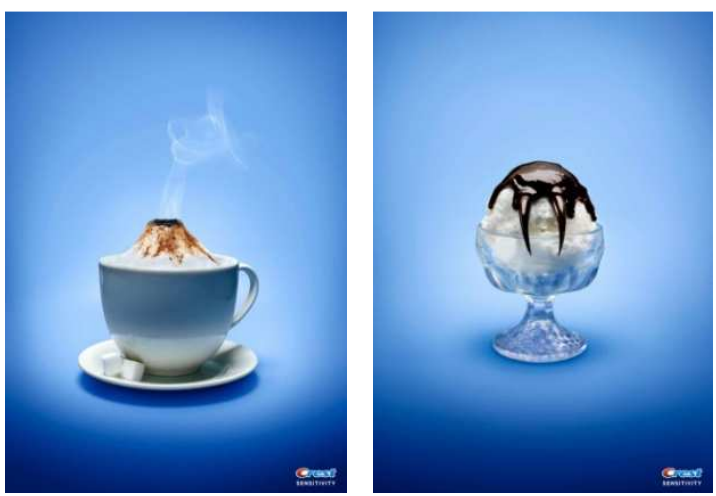

(Advertisements obtained from ADVERTOLOG)

Figure 5. Utilitarian product advertisement with negative metaphor.

\subsection{Administration of the Pretest Questionnaire}

Referring to Lutz, Mackenzie, and Blech [24], a questionnaire was formulated from cognitive and emotional 
facets in this study. This questionnaire consisted of six items (three for cognitive and three for emotional facets), and a 7-point Likert scale was used after each item for participants to evaluate their advertising preference. Before the formal experiment, this study involved selecting 30 undergraduate students to conduct a questionnaire pretest based on the print advertisements of coffee (symbolic product) and shampoo (utilitarian product). Subsequently, Cronbach's $\alpha$ was performed to test reliability of the retrieved questionnaires. The internal consistency reliabilities for cognitive preference, emotional preference, and the overall questionnaire were $\alpha$ $=.902, \alpha=.897$, and $\alpha=.918$, respectively, all reaching a level of high reliability $(\alpha \geq 0.7)$. Accordingly, this questionnaire was employed in the formal experiment.

\subsection{Participants and Experiment}

Through purposive sampling, participants were sampled from the undergraduate and graduate students of the departments of business administration, industrial design, and visual communication design from three universities in Taiwan. The formal experiment was conducted in the form of group sessions. Each session consisted of 60 participants, with 15participants allocated to each experimental condition. The age of the participants ranged between 20 and 27 years $(23.6$ years on average). A total of 240 valid questionnaires were retrieved $(\mathrm{men}=116$; female $=124)$ from $75(31.2 \%), 78$ $(32.5 \%)$, and 87 (36.3\%) participants from the departments of business administration, industrial design, and visual communication design, respectively.

Before the formal experiment, the eight experimental advertisements were uniformly printed in the size of $20.5 \times$ $26.5 \mathrm{~cm}$ and divided into the four experimental conditions, with each condition containing two serial advertisements of the same product type and message framing. The entire experiment lasted approximately 35 minutes, beginning from the researchers' instructions to questionnaire completion. The participants were not permitted to engage in discussions with one another during the experiment. During the instructions, the participants were informed not of the true purpose of this experiment but that this study was related to advertising evaluation. Thereby, the participants could respond to the advertisements most naturally and realistically to reduce possible respondent-induced experimental errors.

Table 1. The description of experiment conditions.

\begin{tabular}{|c|c|c|c|}
\hline Experiment conditions & Product type & Message framing & Advertisement content \\
\hline $\begin{array}{l}\text { Condition A } \\
\text { (Figure 2) }\end{array}$ & Symbolic product & Positive metaphor & $\begin{array}{l}\text { The advertisement depicts a boyfriend and girlfriend kissing, implying that } \\
\text { chewing the chewing gum can effectively remove bad breath and strengthen } \\
\text { their relationship. }\end{array}$ \\
\hline $\begin{array}{l}\text { Condition B } \\
\text { (Figure 3) }\end{array}$ & Utilitarian product & Positive metaphor & $\begin{array}{l}\text { The advertisement presents a picture of a coffee cup and popsicle being crushed } \\
\text { by a cross and people's frightened expressions, implying that the use of this } \\
\text { toothpaste can effectively control annoying, hypersensitive teeth. }\end{array}$ \\
\hline $\begin{array}{l}\text { Condition C } \\
\text { (Figure 4) }\end{array}$ & Symbolic product & Negative metaphor & $\begin{array}{l}\text { The advertisement presents an image of an onion and fish scale, implying that } \\
\text { not chewing the chewing gum will cause your breath to be as foul as onions and } \\
\text { fish. }\end{array}$ \\
\hline $\begin{array}{l}\text { Condition D } \\
\text { (Figure 5) }\end{array}$ & Utilitarian product & Negative metaphor & $\begin{array}{l}\text { The advertisement presents a picture that group volcano with coffee, ice cream, } \\
\text { and venomous fangs to imply the occurrence of dentin hypersensitivity any } \\
\text { time people have hot drinks or ice cream if they do not use this toothpaste. }\end{array}$ \\
\hline
\end{tabular}

\section{Results}

\subsection{Descriptive Statistics}

Regarding the two independent variables' scores for the dependent variable, advertising preference, symbolic product and utilitarian product (advertised product type) scored a mean of $3.95(S D=.72)$ and $3.71(S D=.91)$.

Positive metaphor and negative metaphor (metaphorical message framing) scored a mean of $3.92(S D=.81)$ and 3.72 $(S D=.84)$, respectively (Table 2$)$.

An independent samples $t$-test was conducted to test the influence of metaphorical message framing and advertised product type on advertising preference. According to the test results, when $t=2.02$ and $d f=238$, the influence of metaphorical message framing reached a significant level of $p$ $<.05(p=.045)$, with the advertising preference for positive metaphor exceeding that for negative metaphor ( $M$ positive metaphor $=3.92>M_{\text {negative metaphor }}=3.72$ ). When $t=2.07$ and $d f$ $=238$, the influence of advertised product type reached a significant level of $p<.05(p=.04)$, with the advertising preference for symbolic product surpassing that for utilitarian product $\left(M_{\text {symbolic product }}=3.95>M_{\text {utilitarian product }}=3.71\right)$. These results indicated that advertised product type and metaphorical message framing were factors that individually influenced advertising preference.

\subsection{Influences of the Independent Variables on the Dependent Variable}

Two-way analysis of variance revealed that the $F$ value of the reciprocal influences between the two independent variables and the dependent variable $(\mathrm{A} \times \mathrm{B})$ reached a significant level of $p<.001(F=39.39 ; p=.000$; Table 3$)$. This result indicated an interaction between the two independent variables that influenced advertising preference. Afterward, the simple main effect test was performed to investigate the level of influence that the two independent variables exerted on the dependent variable. If the simple main effect was significant, a posteriori comparisons were conducted with the mean scores of the variables to determine the causal relationships between the two independent 
variables with the dependent variable.

Table 2. Summary of the mean and standard deviation.

\begin{tabular}{lllll}
\hline \multirow{2}{*}{ Variables Source } & \multicolumn{3}{l}{ Advertising preference } \\
\cline { 2 - 4 } & & $\mathbf{n}$ & $\boldsymbol{M}$ & $\boldsymbol{S D}$ \\
\hline \multirow{2}{*}{ Message } & Positive metaphor & 120 & 3.92 & .81 \\
framing & Negative metaphor & 120 & 3.72 & .84 \\
& Total & 240 & & \\
\multirow{2}{*}{ Product } & Symbolic product & 120 & 3.95 & .72 \\
type & Utilitarian product & 120 & 3.71 & .91 \\
\hline
\end{tabular}

According to the results of the simple main effect test (Table 4), product type significantly affected the participants' advertising preference in metaphorical advertisements through the use of either a positive or negative metaphor (positive metaphor, $F(1,118)=7.69, p<.05$; negative metaphor, $F(1,118)=38.49, p<.05)$. Symbolic products advertised with a negative metaphor gained greater advertising preference than did those advertised with a positive metaphor $\left(M_{\text {negative metaphor }}=4.14>M_{\text {positive metaphor }}=\right.$ 3.73).

Utilitarian products advertised with a positive metaphor received greater advertising preference than did those advertised with a negative metaphor $\left(M_{\text {positive metaphor }}=4.12>\right.$ $\left.M_{\text {negative metaphor }}=3.29\right)$. In addition, message framing significantly affected advertising preference when used for symbolic and utilitarian product types in metaphorical advertisements (symbolic product, $F(1,118)=9.96, p<.05$; utilitarian product, $F(1,118)=30.85, p<.001)$. Utilitarian products using a positive metaphor attracted greater advertising preference compared with symbolic products using a positive metaphor $\left(M_{\text {utilitarian product }}=4.12>M_{\text {symbolic }}\right.$ product $=3.71)$, whereas symbolic products using a negative metaphor gained greater advertising preference compared with utilitarian products using a negative metaphor $\left(M_{\text {symbolic }}\right.$ product $=4.13>M_{\text {utilitarian product }}=3.29$ ).

Table 3. The effects of message framing and product type on advertising preference.

\begin{tabular}{lllllll}
\hline Variables Source & & SS & $d f$ & MS & F & Sig. \\
\hline Message framing (A) & $\mathrm{SS}_{\mathrm{a}}$ & 2.75 & 1 & 2.75 & 4.78 & $.030^{*}$ \\
Product type (B) & $\mathrm{SS}_{\mathrm{b}}$ & 2.89 & 1 & 2.89 & 5.03 & $.026^{*}$ \\
$\mathrm{~A} \times \mathrm{B}$ & $\mathrm{SS}_{\mathrm{ab}}$ & 22.61 & 1 & 22.61 & 39.39 & $.000^{* *}$ \\
Error term & $\mathrm{SS}_{\mathrm{s} \text { ab }}$ & 135.48 & 236 & .57 & & \\
\hline
\end{tabular}

${ }^{*} p<.05{ }^{* *} p<.001$

Table 4. The simple main effects of message framing and product type on advertising preference.

\begin{tabular}{lllllll}
\hline Variables Source & SS & df & MS & $\boldsymbol{F}$ & Sig. & Post-hoc \\
\hline Message framing $\left(\mathrm{SS}_{\mathrm{a}}\right)$ & & & & & & \\
in B1 (Symbolic product) & 4.80 & 1 & 4.80 & 9.96 & $.002^{*}$ & $\mathrm{~A} 2>\mathrm{A} 1$ \\
in B2 (Utilitarian product) & 20.56 & 1 & 20.56 & 30.85 & $.000^{* *}$ & $\mathrm{~A} 1>\mathrm{A} 2$ \\
Product type ( $\mathrm{SS}_{\mathrm{b}}$ ) & & & & & \\
in A1 (Positive metaphor) & 4.67 & 1 & 4.67 & 7.69 & $.006^{*}$ & $\mathrm{~B} 2>\mathrm{B} 1$ \\
in A2 (Negative metaphor) & 20.83 & 1 & 20.83 & 38.49 & $.000^{* *}$ & $\mathrm{~B} 1>\mathrm{B} 2$ \\
\hline
\end{tabular}

${ }^{*} p<.05{ }^{* *} p<.001$

\section{Discussion}

\subsection{Influence of Metaphorical Message Framing}

Metaphorical message framing was adopted as the first independent variable to examine its influence on advertising preference. According to the experimental results, the message framing of metaphorical advertisements affected advertising preference, and the participants preferred advertisements containing positive metaphors to those containing negative metaphors. Therefore, H1 was verified.

Although previous studies have indicated that negative messages can induce people's attention and mental effort more easily $[35,37,36]$, this study found that, regarding metaphorical messages, consumers preferred positive metaphors to negative metaphors. According to Wong and McMurray [40], negative messages issue warnings to people and attract the audience's attention more easily than positive messages do. Furthermore, negative messages can prompt the audience to process information more actively because everyone is afraid of negative news becoming true, which corresponds with the psychological phenomenon of risk seeking in prospect theory [39]. However, regarding message preference, positive messages seemed to capture the audience's emotions more easily than negative messages did. Moreover, Tversky and Kahneman [39] argued that people display risk-averse behavior when facing positive messages. Therefore, this current study inferred that consumers' level of preference for metaphorical message framing was associated with their risk-averse attitude toward messages.

Metaphors are derived from analogies, in which similarities between objects are compared to infer metaphorical meanings. The level of similarity between a metaphorical target and vehicle can be generalized as the mapping between two objects [18] and as the conceptual relationship or consistency of objects. Furthermore, distance in the relationship between objects or concepts can affect the cognitive outcomes of 
message receivers [8]. In other words, metaphor is partially related, instead of completely equivalent, to the target and vehicle (i.e., "A is similar to B" instead of "A is B"). This cross-conceptual domain comparison [19], when used in advertisements, may result in a creative communication or risk of not being understood by the audience. When consumers do not comprehend advertisements, they display a relatively low advertising preference. Accordingly, this study further examined the positive metaphors adopted in the advertisements and inferred that product benefits were recognized using a two-step analogical method (e.g., a vampire and a cross sensitive teeth and anti-sensitivity toothpastes). This analogical method can easily guide consumers to comprehend the content of an advertisement, after which their advertising preference may be enhanced.

\subsection{Influence of Metaphorical Advertised Product Type}

Advertised product type was used as the second variable to investigate its influence on advertising preference. The experimental results indicated that the factor of product type in metaphorical advertisements affected advertising preference, and the participants preferred advertisements for symbolic products to those for utilitarian products. Therefore, $\mathrm{H} 2$ was verified.

Generally, symbolic products create emotions and pleasure in consumers; therefore, consumers using these products can demonstrate their real characteristics or fulfill their ideal self-images in daily life [17]. Mano and Oliver [27] considered that consumers generally focus on their experience of sensing the aesthetic characteristics, symbolic meanings, and evoked emotions of a symbolic product when evaluating its benefits. Isen [13] further indicated that emotions, in addition to influencing attention, are associated with the level of preference for objects. Particularly, positive emotions directly influence the enhancement of attention and preference. Associating these conclusions with the experimental results of this study, we considered that symbolic products exerted the emotional effects of self-expression and sign-consumption. Furthermore, compared with utilitarian products, symbolic products stimulate more imaginative and positive consumer emotional reactions to product benefits and may therefore enhance their advertising preference.

Regarding advertising design tactics, whether an advertisement can realize its persuasive power depends on whether the visual images presented can cause emotional changes in consumers. Symbolic products are inherently emotionally catalytic, and advertising messages are conveyed using visual metaphorical techniques. Therefore, this study argued that, after identifying product benefits through metaphorical images, consumers can enhance their experience and project the effects of metaphor onto the imagination of product benefits. Thus, dramatic tension and positive emotions are created in advertising messages, which then facilitate advertising preference. Moreover, according to Ang and Lim [1], using metaphor to convey advertising messages for a symbolic product can enhance brand personality perceptions and reinforce consumer attitudes toward the advertisement. However, this study believed that consumers react positively in cognitive and emotional terms to advertisements before exhibiting favorable brand personality perceptions and attitudes toward the advertising messages. Regarding whether the use of metaphors in advertisements results in relatively less satisfactory advertising preference for utilitarian products, further investigations must be performed.

\subsection{Interaction Effect of Message Framing and Product Type}

The experimental results revealed an interaction between the two independent variables that influenced advertising preference. In other words, a symbolic product using a negative metaphor acquired a higher level of advertising preference than did that using a positive metaphor, whereas a utilitarian product adopting a positive metaphor achieved a higher level of advertising preference than did that using a negative metaphor. According to these results, the influences that the internal factors of the two independent variables exerted on the dependent variable resulted in opposite experimental results. Therefore, $\mathrm{H} 3$ and $\mathrm{H} 4$ were verified.

Soliha and Dharmmesta [38] indicated that negative message framing corresponds with people's expectation of avoiding negative news, whereas positive message framing conflicts with this expectation. Therefore, compared with positive messages, people tend to scrutinize negative messages more exhaustively. Nevertheless, Buda and Zhang [4] found that positive message framing is more strongly associated with consumer attitudes toward products than with negative messages. In addition, Smith and Petty [36] argued that positive message framing is more persuasive than negative message framing and can induce more positive consumer attitudes. Associating the experimental results with the results of these studies, we inferred that, although the target and vehicle in metaphorical advertisements using analogy to convey messages demonstrated numerous similarities, various differences existed between them. Furthermore, metaphorical advertisements expanded the scale of imagination in consumers, and different product types seemed to guide consumers to follow different message framings in interpreting the arguments presented in the metaphorical advertisements, which resulted in different levels of advertising preference.

By applying the prospect theory to interpret the experimental results [39], we determined that symbolic products (e.g., chewing gum) in metaphorical advertisements seemed to be able to evoke risk-seeking psychological phenomena in consumers. Therefore, negative metaphorical framing, when used on symbolic products, fulfilled consumers' expectation of preventing bad breath. Conversely, utilitarian products seemed to induce risk-averse psychological phenomena in consumers and prompt them to accept the positive advertising argument of combating dentin hypersensitivity; therefore, positive metaphor framing combined with the benefits of utilitarian products can generate relatively more satisfactory message attitudes in consumers. According to the interaction between the variables of product 
type and message framing indicated in the experimental results, positive metaphorical advertisements can effectively enhance the advertising preference for utilitarian products, whereas negative metaphorical advertisements can effectively increase the advertising preference for symbolic products. Although previous studies have determined that metaphorical images stimulate superior message attitudes in consumers [28, $30]$, this study further investigated the influence of metaphorical message framing on product type. The experimental results can enable advertisers to engage in in-depth thinking and serve as solid references for them to formulate message strategies or practice creativity in the future.

\section{Conclusion}

Advertising is a process of persuasion and communication that conveys meaning through texts and images. Therefore, pictures and words can be regarded as the metaphors for products, the vehicles of advertising messages, and furthermore, the sources for conveying crucial product information. Therefore, graphic and textual designs are extremely critical to an advertisement. If pictures and words are inappropriately employed or designed in advertisements, they would fail to convince the audience and even affect public perception toward advertised products. Previous studies have indicated that using metaphors can enhance advertising preference and persuasiveness. However, metaphorical graphic and textual designs are a type of destabilization trope [29] and contradictory association [21] as well as the cognitive results obtained through learning of the experiential similarities between objects and the mapping between the target and vehicle [19]. Therefore, this advertising tactic does not necessarily apply to all product types and consumers. Moreover, although previous studies have revealed the satisfactory effects of metaphorical advertisements, this study determined that different metaphorical message framings and product types affected the reactions of consumers to messages. Consequently, we suggest that advertisers adopt different persuasive techniques and strategies according to product attributes to produce advertising effects.

The persuasive process of advertisements involves consumers' cognitions, emotions, and behavior reactions toward messages [20]. Concerning this process, product attributes are extremely crucial because they motivate consumers to make different behavioral decisions as a result of messages delivered by the advertisements. Regarding product type, symbolic products are perceived to be more sophisticated and exciting compared with utilitarian products [1]. If the factor of message framing is disregarded, metaphorical persuasive tactics seem to be more suitable for symbolic products than for utilitarian products because metaphors are used to evoke emotions in consumers [30]. Therefore, symbolic products seem to share a certain level of commonality with the objectives of metaphorical advertisements. However, according to the theory of message framing effects, the positive or negative framings of a message result in different decision-making behaviors. Furthermore, studies on metaphorical advertisements have mostly confirmed their strong persuasiveness; nevertheless, most studies have not included the factor of metaphorical message framing, leading to inconclusive results that demanded further investigation. This study examined the factor and determined that positive metaphorical advertisements can effectively enhance the advertising preference for utilitarian products, whereas negative metaphorical advertisements can effectively increase the advertising preference for symbolic products. Compared with the results of previous studies on metaphorical advertisements, the results yielded in this study can provide advertising practitioners with clear references for advertising and marketing projects.

Previous studies have indicated that metaphors exhibiting high persuasiveness are the most effective means for designers to stimulate creativity. In addition, advertisers frequently employ metaphorical advertisements to convince the public. Nevertheless, the processing of metaphorical messages is a complex cognitive reaction [8], and the positive or negative framings of a message affect consumers' value preference imperceptibly and their final decision making. Furthermore, regardless of how metaphorical messages are framed, they always concern product benefits and the common life experiences of the public as these are the only ways for metaphorical advertisements to be effective. Finally, regarding advertising tasks, skills and strategies are required for an advertisement to convince and affect consumers. Most audiences adopt a guarded attitude toward advertising messages. Although metaphors are a persuasive tool to break consumer psychological defense, optimizing the persuasiveness of metaphorical advertisements still depends on metaphorical message framing and product type. This study focused on involvement levels to investigate the influences of metaphorical message framing and product involvement on brand personality perceptions to provide valuable references for advertising design practice and advertising message strategies.

\section{Acknowledgements}

The author gratefully acknowledges the support for this research provided by the Ministry of Science and Technology of Taiwan under Grants No. MOST-103-2410-H-131-001.

\section{References}

[1] Ang, S. H., \& Lim, E. A. C. (2006). The influence of metaphors and product type on brand personality perceptions and attitudes. Journal of Advertising, 35(2), 39-53.

[2] Black, M. (1962). Models and metaphors: Studies in language and philosophy. Ithaca, New York: Cornell University Press.

[3] Boozer, R. W., Wyld, D. C., \& Grant, J. (1992). Using metaphor to create more effective sales messages. The Journal of Business and Industrial Marketing, 7(1), 19-27. 
[4] Buda, R., \& Zhang, Y. (2000). Consumer product evaluation: The interactive effect of message framing, presentation order, and source credibility. Journal of Product \& Brand Management, 9(4), 229-242.

[5] Cotte, J., Coulter, R. A., \& Moore, M. (2005). Enhancing or disrupting guilt: The role of ad credibility and perceived manipulative intent. Journal of Business Research, 58(3), 361-368.

[6] Ganzach, Y., \& Karsahi, N. (1995). Message framing and buying behavior: A field experiment. Journal of Business Research, 32(1), 11-17.

[7] Gentner, D., \& Markman, A. B. (1997). Structure mapping in analogy and similarity. American Psychologist, 52(1), 45-56.

[8] Grewal, D., Gotlieb, J., \& Marmorstein. H. (1994). The moderating effects of message framing and source credibility on the price-perceived risk relationship. Journal of Consumer Research. 21 (6), 145-153.

[9] Haley, R. I., \& Baldinger, A. L. (1991). The ARF copy research validity project. Journal of Advertising Research, 31(2), 11-32.

[10] Hirschman, E. C. (1980). Attributes and layers of meaning. Advances in Consumer Research, 7, 101-118.

[11] Holbrook, M. B. (1986). Emotion in the consumption experience: Toward a new model of the human consumer, In The Role of Affect in Consumer Behavior: Emerging Theories and Applications, Robert A. Peterson, Wayne D. Hoyer, and William R. Wilson (eds.), Lexington, MA: D.C. Heath.

[12] Isen, A. M. (2000). Some perspectives on positive affect and self-regulation. Psychological Inquiry, 11(3), 184-187.

[13] Jeong, Se-Hoon (2008). Visual metaphor in advertising: Is the persuasive effect attributable to visual argumentation or metaphorical rhetoric?. Journal of Marketing Communications, 14(1), 59-73.

[14] Kaplan, S. J. (1992). A conceptual analysis of form and content in visual metaphors. Communication, 13(33), 197-209.

[15] Kardes, F. R. (1988). Spontaneous inference processes in advertising: The effects of conclusion omission and involvement on persuasion. Journal of Consumer Research, $15(2), 225-233$

[16] Khalil, E. L. (2000). Symbolic products: Prestige, pride, and identity goods. Theory and Decision. 49 (1), 53-77.

[17] Kövecses, Zoltán (2002). Metaphor: A practical introduction. New York: Oxford University Press.

[18] Lakoff, G., \& Johnson, M. (1980). Metaphor we live by. Chicago: University of Chicago Press.

[19] Lavidge, R., \& Steiner, G. (1961). A model for predictive measurements of advertising. Journal of Marketing, 25(6), 59-62.

[20] Leigh, J. H. (1994). The use of figures of speech in print ad headlines, Journal of Advertising, 23(2), 17-23.

[21] Levin, I., \& Gaeth, G. J. (1988). How consumers are affected by the framing of attribute information before and after consuming the product. Journal of Consumer Research, 15(3), 374-378.

[22] Lutz, R. J. (1980). Changing brand attitudes through modification of cognitive structure. Journal of Consumer Research, 1(4), 49-59.

[23] Lutz, R. J., Mackenzie, S. B., \& Blech, G. E. (1986). Attitude toward the ad as a mediator of ad effectiveness: determinates and consequences. Advance in Consumer Research, 10, $532-539$.

[24] MacInnis, D. J., Moorman, C., \& Jaworski, B. J. (1991). Enhancing and measuring consumers' motivation, opportunity, and ability to process brand information from ads. Journal of Marketing, 55(4), 32-53.

[25] Maheswaran, D., \& Meyers-Levy, J. (1990). The influence of message framing and issue involvement. Journal of Marketing Research, 27(3), 361-367.

[26] Mano, H., \& Oliver, R. L. (1993). Assessing the dimensionality and structure of the consumption experience: evaluation, feeling, and satisfaction. Journal of Consumer Research. 20(4), 451-466.

[27] McQuarrie, E. F. \& Mick, D. G. (2003). Visual and verbal rhetorical figures under directed processing versus incidental exposure to advertising. Journal of Consumer Research, 29(4), $579-587$.

[28] McQuarrie, E. F. \& Mick, D. G. (1996). Figures of rhetoric in advertising language. Journal of Consumer Research, 22(4), 424-437.

[29] McQuarrie, E. F. \& Phillips, B. J. (2005). Indirect persuasion in advertising: how consumers process metaphors presented in pictures and words. Journal of Advertising, 34(2), 7-20.

[30] Meyerowitz, B. E., \& Chaiken, S. (1987). The effect of message framing on breast self-examination attitudes, intentions, and behavior. Journal of Personality and Social Psychology, 52(3), 500-510.

[31] Morgan, S. E., \& Reichert, T. (1999). The message is in the metaphor: Assessing the comprehension of metaphors in advertisements. Journal of Advertising, 28(4), 1-12.

[32] Ortony, A., Schallert, D., Reynolds, R., \& Antos, S. (1978). Interpreting metaphors and idioms: Some Effects of context on comprehension. Journal of Verbal Learning and Verbal Behavior, 17(4), 465-477.

[33] Pawlowski, D. R., Badzinski, D. M., \& Mitchell, N. (1998). Effects of metaphors on children's comprehension and perception of print advertisements. Journal of Advertising, 7(2), $88-98$

[34] Pratto, F., \& John, O. P. (1991). Automatic vigilance: The attention-grabbing power of negative social information. Journal of Personality and Social Psychology, 61(3), 380-391.

[35] Smith, S. M., \& Petty, R. E. (1996). Message framing and persuasion: A message processing analysis. Personality and Social Psychology Bulletin, 22(3), 257-268.

[36] Skowronski, J. J., \& Carlston, D. E. (1987). Social judgment and social memory: The role of cue diagnosticity in negativity, positivity, and extremity biases. Journal of Personality and Social Psychology, 52(4), 689-699.

[37] Soliha, E., \& Dharmmesta, B. S. (2012). The Effect of source credibility and message framing on consumer risk perceptions with consumer product knowledge as a moderating variable: A literature review. Educational Research, 3(2), 108-117. 
[38] Tversky, A., \& Kahneman, D. (1981). The framing of decisions and the psychology of choice. Science, 211(30), 453-458.

[39] Wong, C. O., \& McMurray, N. E. (2002). Framing communication: Communicating the antismoking message effectively to all smokers. Journal of Community Psychology, 30(4), 433-447.

[40] Vaughn, R. (1980). How advertising works: a planning model. Journal of Advertising Research, 20(5), 27-33.
[41] Woods, W. (1960). Psychological dimensions of consumer decision. Journal of Marketing, 24 (1), 15-19.

[42] Zaltman, G. (1995). Amidword: anthropology, metaphors, and cognitive peripheral vision, In Contemporary Marketing and Consumer Behavior: An Anthropological Source Book, John E. Sherry, Jr., (ed.), Thousand Oaks, CA: Sage, 282-304.

[43] Zhang, Y., \& Buda, R. (1999). Moderating effects of need for cognition on responses to positively versus negatively framed advertising messages. Journal of Advertising, 28(2), 1-15. 